\title{
Risk management on an alluvial fan: a case study of the 2008 debris-flow event at Villar Pellice (Piedmont, N-W Italy)
}

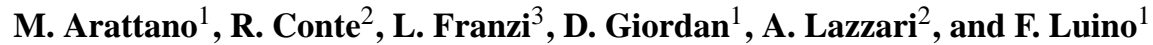 \\ ${ }^{1}$ Italian National Research Council, Istituto di Ricerca per la Protezione Idrogeologica, Torino, Italy \\ ${ }^{2}$ Regione Piemonte, Civil Protection Department, Torino, Italy \\ ${ }^{3}$ Regione Piemonte, Public Works, Soil Defence Department, Torino, Italy
}

Received: 19 November 2009 - Revised: 23 February 2010 - Accepted: 4 March 2010 - Published: 10 May 2010

\begin{abstract}
In the Piedmont Region (North-Western Italy), the regional authorities manage debris flow risk by following the ideal sequence of steps that are generally pursued in land planning and civil protection activities. Complex procedures and methods are elaborated and widely discussed with politicians, economists and the general public. On the contrary, in emergency situations, civil protection agencies generally prefer the adoption of simple and flexible criteria. In this paper, a catastrophic debris flow event, that occurred in 2008 in Villar Pellice, is described in this perspective, after an analysis of the triggering rainfalls and of the effects on human life and properties. The availability of a series of personal accounts coming from people who witnessed the occurrences before, during and after the event has allowed us to analyse, in detail, the dynamics of the event. Thanks to these accounts, it has been possible to propose new guidelines for the planning of the emergency activities in areas that are potentially prone to similar impulsive phenomena.
\end{abstract}

\section{Introduction}

The hazard mapping techniques commonly used in the Piedmont Region generally rely on the collection of field data, the execution of field surveys and the application of models to identify the debris-flow prone areas on the alluvial fans. Then decision makers follow procedures that allow the finding of the most profitable countermeasures to reduce the hazards and the risk, as well as to monitor the processes on the alluvial fans. Time availability allows the government officers to apply and elaborate on, if necessary, complex procedures and methods and to extensively discuss solutions with politicians, economists and the general public.

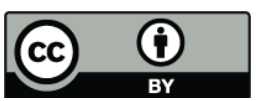

Correspondence to: L. Franzi (luca.franzi@ regione.piemonte.it)
However, in emergency situations, just before or soon after the occurrence of a debris-flow process, the authorities cannot follow similar strategies to take their most urgent decisions and manage both hazard and risk. Actually, the lack of time often forces officers and decision makers to rapidly choose solutions to mitigate the risk. Moreover, due to the complexity of the situations that have to be managed (assessment of the residual risk, design of countermeasures, etc.), the coordination of engineers, geologists and practitioners plays one of the most important roles in the management of the residual risk.

The efficiency and the effectiveness of both the territorial planning and the civil protection strategies have been tested during a recent debris-flow event, which occurred on 29 May 2008 in the locality of Garin, in the Villar Pellice municipality (near Turin). Periodically, the occurrence of catastrophic events forces regional and local authorities to make a revision of hazard mapping, as well as discuss the efficiency of civil protection procedures and the Garin debris flow was certainly one of these events. Thus, we will examine, in this paper, the improvements that are needed to better face the future in similar occurrences.

The 29 May 2008 debris flow caused tragic effects: four casualties, three persons injured, four buildings and three cars (among which an ambulance) hit by the debris flow (Figs. 1 and 2).

This specific event was the most devastating among those that occurred during a large meteorological event (2830 May 2008) that affected, in particular, the Turin and $\mathrm{Cu}-$ neo Provinces, causing floods on the main valley bottom, some debris flows and a great number of landslides with damages, particularly to the road system. The Villar Pellice event was the most destructive, and the only one that caused casualties.

The debris flow was triggered by heavy rainfalls and took place in a very small watershed $\left(0.68 \mathrm{~km}^{2}\right)$, incised by a very steep creek (mean basin slope $44^{\circ}$ ) named Cassarot, $1.4 \mathrm{~km}$

Published by Copernicus Publications on behalf of the European Geosciences Union. 


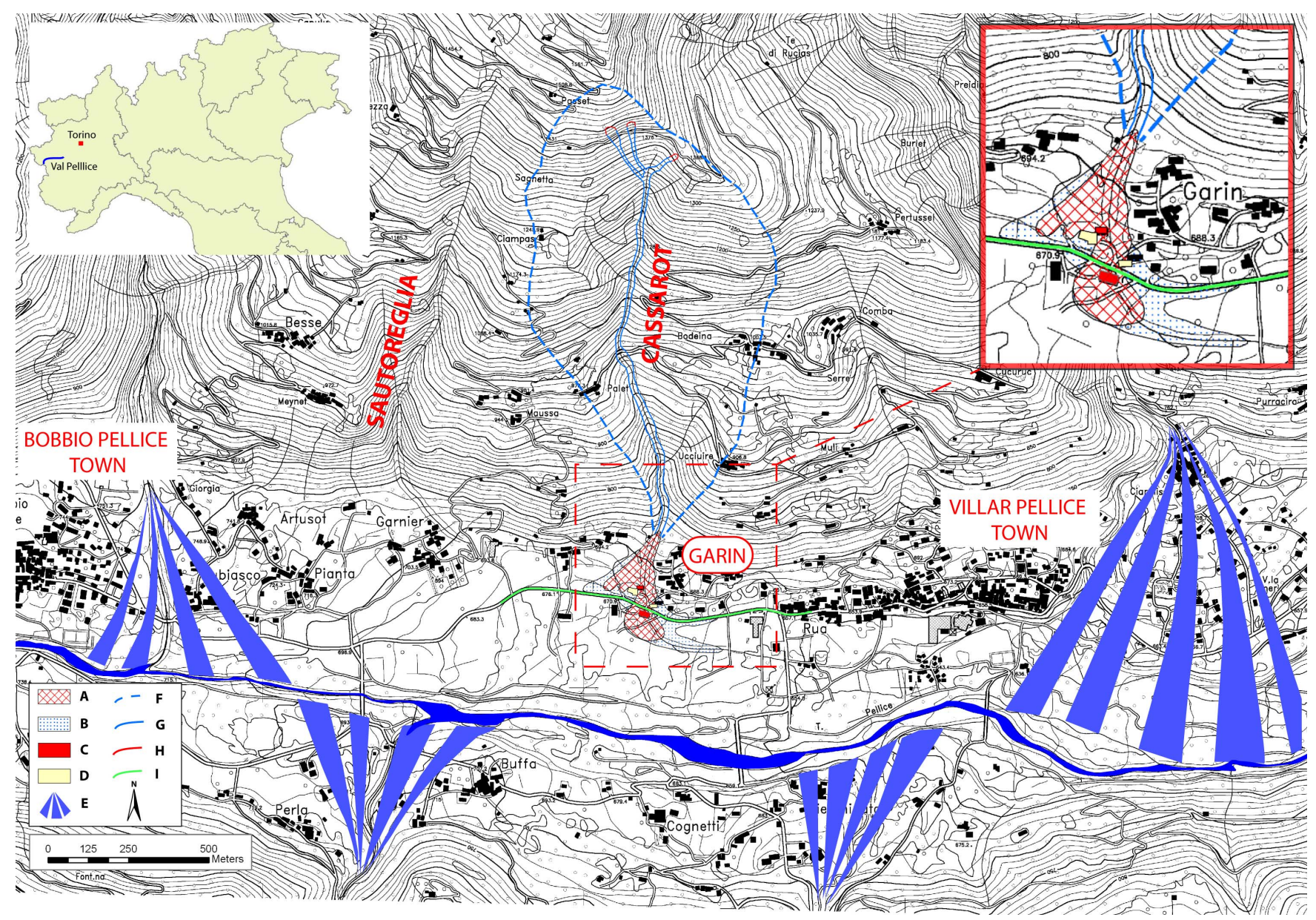

Fig. 1. Location of Villar Pellice and Cassarot creek, North-Western Italy. A - debris flow deposit area; B - area flooded by debris flow ; C - houses destroyed; D - houses seriously damaged; E - main alluvial fan; F - Cassarot basin; G - deep erosive scar left by the debris flow; $\mathrm{H}$ - main soil slips triggering the debris flow; and I - Road S.P. 161.

long, that is a tributary of the Pellice river. The fan was historically flooded in the past and also recently; in particular, the most recent events took place in May 1977 and October 2000. The 1977 event (Tropeano et al., 1999) represents the most important event of the nineteen century in the Pellice Valley, but, with regard to the Garin alluvial fan, the damages were not so heavy as in 2008; the 2000 event represents one of the most important events in north Piedmont (Tropeano et al., 2000; Barredo, 2007), but in this area the damage was very limited if comparing it to the 2008 event. In Italy, for historical reasons, many villages originally arose on the alluvial fans, avoiding the occupation of the valley floor, where the frequency of the flood occurrence would have needed the construction of expensive defensive countermeasures. However, the relatively low frequency of occurrences of debris flow is deceptive, considering that debris flows are generally more destructive than floods and much more unpredictable.

\section{Meteorological conditions of the 28-30 May event}

In the second half of May 2008, on the Prealps and Alps of Piedmont and Val d'Aosta, diffuse and locally very intense rainfalls were recorded. Such conditions were due to the progressive deepening on the eastern Mediterranean sea of a deep Atlantic trough in the middle troposphere, which from Great Britain spread to North Africa (ARPA Piemonte, 2008).

In particular, during the last days of May (from 27th to the morning of the 28th), mild and heavy local showers occurred on Piedmont and Val d'Aosta. After a pause of about $12 \mathrm{~h}$, a second phase began that was characterised by intense precipitations over prealpine and alpine sectors of the aforesaid regions: such rainfalls became persistent and stationary during the entire day on 29 May. Snow melting contribution was very important and further increased the torrent flow in the preceding days that added up to intense precipitations. During the main event, the thermal zero remained 


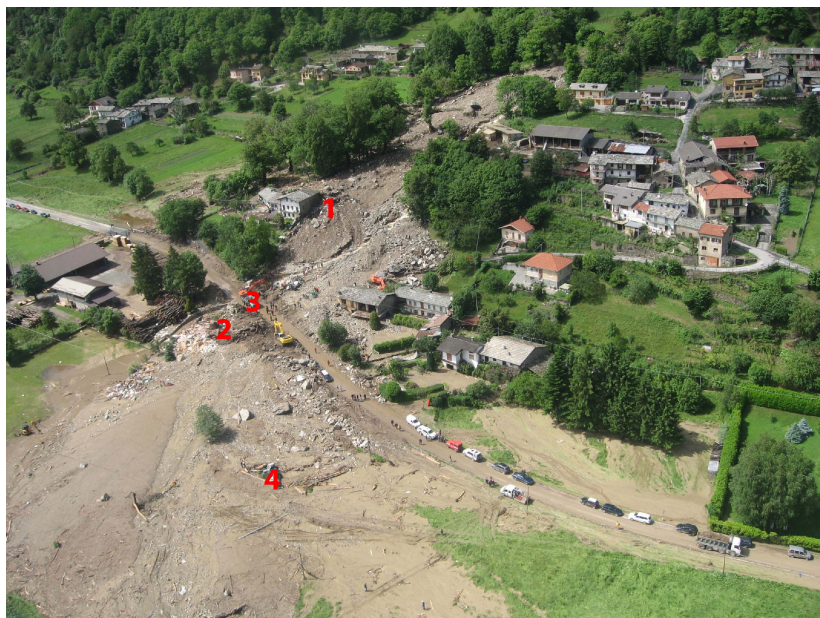

Fig. 2. Aerial view of Garin, affected by the debris flow of Cassarot creek occurred on 29 May 2008. 1 - destroyed house; 2 - more destroyed building; 3 - location where one of the cars hit by the flow was found (the fourth victim); and 4 - location where the ambulance and the tractor, hit by the flow, were found.

at an elevation ranging between 2800 and $3400 \mathrm{~m}$ (28 May). These rainfalls triggered relevant effects like shallow landslides, torrential floods, muddy debris flows, bank erosions and floods on the valley bottoms of the main rivers. Many villages were isolated and numerous road interruptions were counted because of the subsiding, obstructions, erosions and flooding of the roadways.

Weather forecasting by ARPA (the Regional Agency for Environmental Protection) indicated a high alert level, corresponding to the possibility of soil slips, torrent floods and debris-flow occurrence.

Hourly intensities were generally less than $20 \mathrm{~mm} / \mathrm{h}$, with peaks of $50 \mathrm{~mm} / \mathrm{h}$. Cumulated rainfall reached values greater than $200 \mathrm{~mm}$ in a significant amount of raingauges, with a maximum of more than $440 \mathrm{~mm}$ in 4 days (26-29 May) just in the Pellice Valley (Fig. 3), at the Colle Barant raingauge.

In this valley, one of the most hit by the meteorological event, more than $90 \%$ of the cumulated rainfalls for the whole month of May were concentrated between 28 and 30 May 2008 and exceeded 1.5 times the average rainfall of the period 1961-1990. On 29 May, rainfall intensities, up to $88 \mathrm{~mm}$ in $3 \mathrm{~h}$, were measured at the Bobbio Pellice raingauge and, subsequently, in the second half of the day, $172 \mathrm{~mm}$ in $12 \mathrm{~h}$ at the Colle Barant raingauge (2302 m a.s.l.). Hourly rainfall peaks reached the maximum value at the raingauge of Bobbio Pellice $(46 \mathrm{~mm} / \mathrm{h}$ between $09 \mathrm{~h} 00$ and $10 \mathrm{~h} 00)$ just before the debris-flow occurrence (Fig. 3). The Bobbio Pellice raingauge is located at a distance of about $1.7 \mathrm{~km}$ from the Garin village at an elevation of $1313 \mathrm{~m}$ a.s.l., while the head of the Cassarot basin is about $1550 \mathrm{~m}$ a.s.l. On the contrary, the cumulative rainfalls and the maximum intensi-

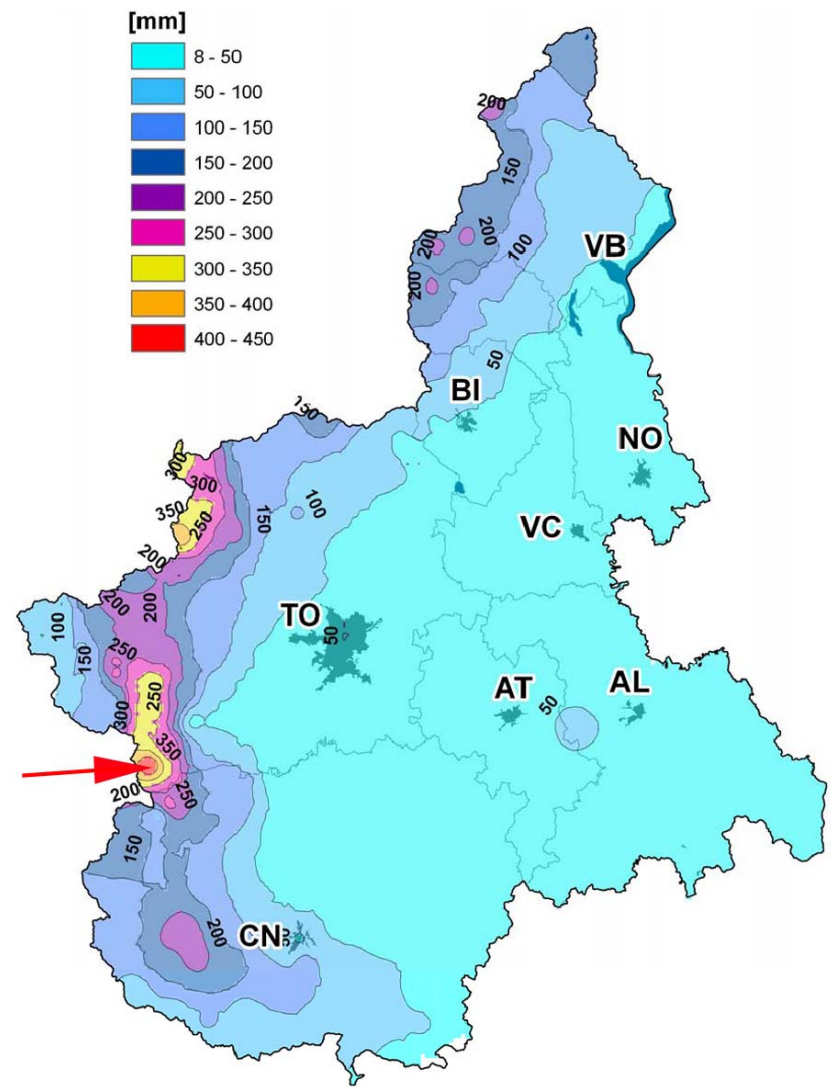

Fig. 3. Total cumulated rainfall isohyets of the event; the red arrow shows the location of the Pellice Valley that corresponds to the sector that was most affected by the rainfalls (from ARPA Piemonte, 2008 modified)

ties recorded at the Luserna San Giovanni raingauge (Fig. 4) are considerably lower. This shows the heterogeneity of the rainfall distributions over the whole valley.

\section{Debris-flow event and surveys}

During the 28-30 May 2008 meteorological event, many soil slips originated in the Pellice Valley, generally triggered above $1500 \mathrm{~m}$ a.s.l. The debris flow in Villar Pellice hit the inhabited areas at $10 \mathrm{~h} 25$ and was preceded by the activation of a series of soil slips that interrupted the viability at different points, making the area inaccessible. The deposits left by the flow covered an area of about $28000 \mathrm{~m}^{2}$, with a maximum thickness of up to $3 \mathrm{~m}$. The estimated total transported volume was about $40000 \mathrm{~m}^{3}$ (Lollino et al., 2008). Four people died, three were in the house destroyed by the debris flow (indicated with number 1 in Fig. 2) and another in a car (number 3 in Fig. 2). Another house was also destroyed (number 2 in Fig. 2) without losses. 


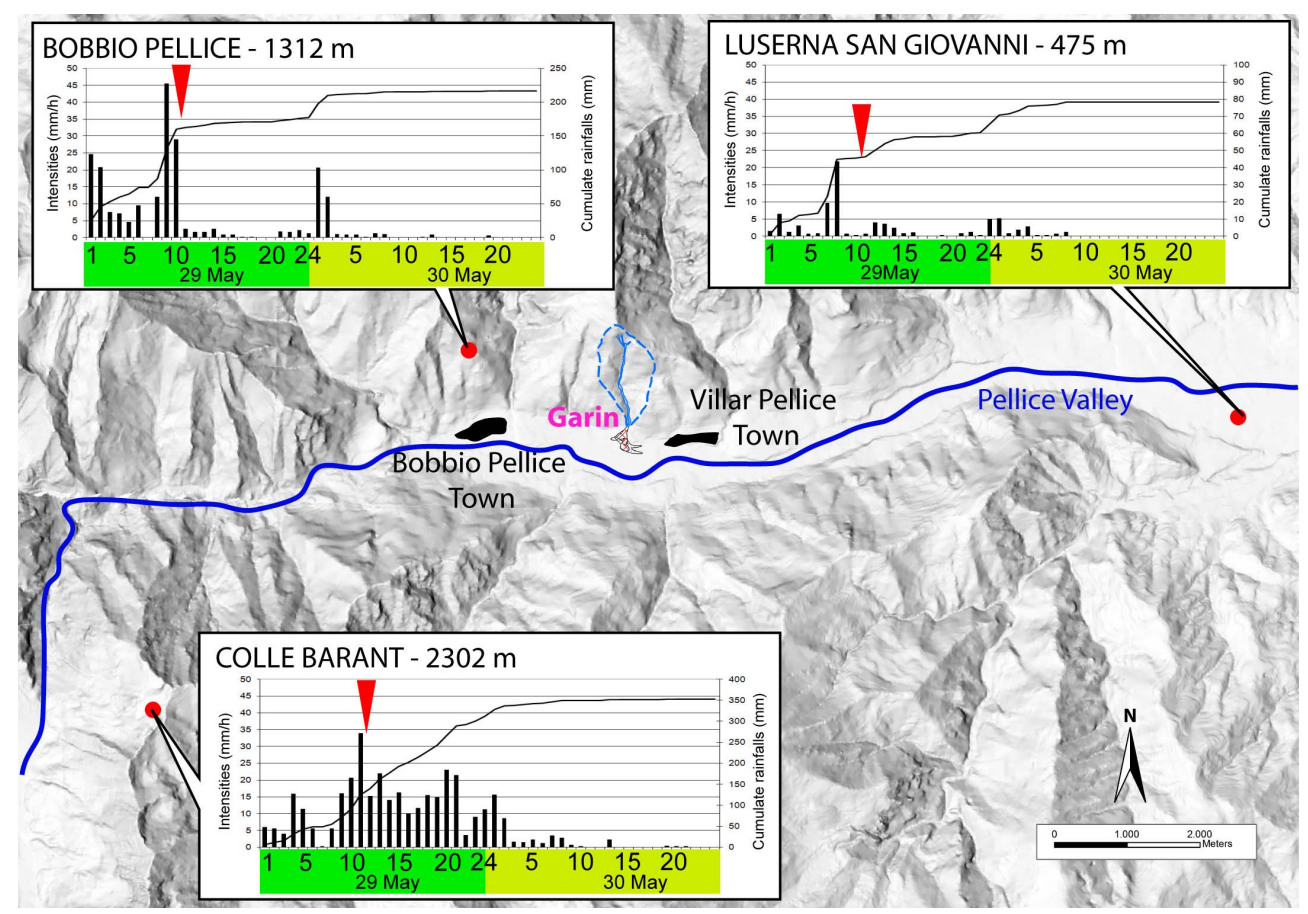

Fig. 4. Location of the raingauges near Villar Pellice with the intensities and cumulated rainfalls on 29-30 May 2009 (the start time for all of the graphs was midnight on 29 May). The comparison of the graphs gives important indications concerning the strong heterogeneity of the rainfalls, as far as their amount and time distribution are concerned. The red arrows shows the debris flow time occurrence.

The debris flow was a natural slope-single failure event (Collins, 2008; Hungr et al., 2001), characterised by the absence of warning signs in the natural slope before the debris flow triggering event.

The Cassarot basin bedrock is made of coarse grain metamorphic rocks that, from the depositional style point-ofview, gives a non-cohesive sediment gravity flow with sheetfloding (Moscariello et al., 2002). The deposit of the debris flow shows a different horizontal gradation along the fan with clast-rich lobes, levee-like boulder train and distal sand-rich lobes that are characteristic of this type of catchment lithology group (Tiranti et al., 2008). Boulders could be found on the alluvial fan apex, while sand and silt in the more distal part. As witnessed by the Villar Pellice inhabitants, the debris flow consisted probably of a single debris wave that was preceded by a loud noise. The tractor and the ambulance on the main road were swept away by a muddy mixture (number 4 in Fig. 2), with a relatively low velocity. The witnesses were not aware of what was going on, even if the water discharge of the Cassarot creek had already flooded the street.

From the very beginning of the emergency management phases, a series of witnesses were contacted and interviewed to better understand the event dynamics and to direct the rescue interventions. This allowed us to trace four particularly important witnesses: a technician of the municipality carried out a survey about $40 \mathrm{~min}$ before the event. According to this survey, the Cassarot creek already showed a very high discharge that was, however, contained within the channel, there were no flood evidences and the road crossings were all practicable.

A carpenter, working in a joinery located upstream of the affected area, was present at the occurrence of the debris flow and described it as a single wave with splashes that were taller than the roofs of the houses (this is confirmed by the mud tracks left on the walls of the houses that were hit but not destroyed by the event). Rainfalls were extremely intense and the torrent flow was no longer contained by the channel but was also flooding the Provincial Road 161 (called S.P. 161).

This latter occurrence was also confirmed by the ambulance driver. His testimony, very lucid and detailed, consisted mainly of a series of pictures: the Cassarot creek was no longer flowing within the channel but was flooding the S.P. 161 road with a flow height of tens of centimetres; debris of different types (wood and pebbles) was present on the roadway. The ambulance crossed the bridge and was hit by the more fluid part of the debris flow. The ambulance was carried off the roadway by this dense fluid. Before the debris flow arrival, there was no evident sign of the imminent event. The velocity of the flow that hit the ambulance was described to be low: the flow was moving at a walking pace.

Similar dynamics were described by a tractor driver who was at a distance of a few metres from the ambulance when the debris flow hit it. It is important to notice that both the 
drivers mentioned the presence of water on the roadway at the moment of the debris flow occurrence, but their behaviour and their testimony also emphasized that they did not have a real perception of the imminent danger.

People who were in the area and observed the evolution of the events preceding the debris flow had a different perception. Among the different collected testimonies, however, only the carpenter working in the joinery showed that he had a feeling of the imminent danger. This is a very important element and will be taken into careful account in the following chapters devoted to the development of the procedures to handle sites affected by this type of phenomenon: only a person who watches the entire evolution of the phenomena could develop a correct perception of the event to make an effective decision.

At the end of the emergency phase, a series of surveys were carried out to better understand the event. These surveys were performed along the entire channel of the Cassarot creek, also using a GPS and a distantiometer. A longitudinal profile of the debris flow path was surveyed together with the width and, where possible, the maximum depth of 35 cross sections (one every $50 \mathrm{~m}$ ). For every surveyed point, a series of sedimentological notations have been taken together with a set of photos. All these elements have been inserted in a GIS specifically realized. These measurements allowed us to calculate, besides the mean basin slope given above, the fan slope $\left(22^{\circ}\right)$ and the slope of the steepest reach of the creek $\left(68^{\circ}\right)$ in the upper basin where a series of shallow landslides triggered the debris flow. Among the latter, the most important is a soil slip located at an elevation of $1350 \mathrm{~m}$ a.s.l. that involves the colluvial debris deposits; starting from this latter point it is possible to follow the continuous incision left by the passage of the debris flow. The latter has deeply incised in patches the deposits of different origins (mostly glacial and gravitational), exposing the rocky substratum. The debris flow path develops for a distance of about $1300 \mathrm{~m}$ and a drop of about $650 \mathrm{~m}$ to the fan apex. The incision left by the flow has a mean width of about $15 \mathrm{~m}$ that reaches a maximum value of $30 \mathrm{~m}$.

\section{Risk assessment and territorial planning}

Debris flow events, similar to that recorded in Villar Pellice, are quite usual in the Piedmont Region, due to the extension of its mountainous areas (more than $40 \%$ out of $25000 \mathrm{~km}^{2}$ ). As in many other parts of the world, soil slips are generally triggered during heavy rains and storms (Franzi and Bianco, 2002; Luino, 2005; Guzzetti et al., 2008), with rainfall thresholds that can be very different from place to place.

In the Piedmont Region, the public administration manages the hydrogeological risks either from the point-of-view of the territorial planning at the basin scale or by means of civil protection plans and interventions. Territorial planning is mostly concerned about risk mapping on alluvial fan areas, with the subsequent issue of resolutions that impose (1) limitations in building constructions (Autorità di Bacino del Fiume Po, 2001), (2) countermeasures (structural or nonstructural) for existing buildings, and (3) civil protection intervention strategies and organization before, during and after catastrophic events.

At a basin scale, debris flow risk assessment and mapping have been made in the framework of the hydrogeological arrangement plan (called PAI - Autorità di Bacino del Fiume Po, 2001) of the Po river watershed basin, by following the steps:

1. delimiting the areas where landslides may occur, at a basin scale;

2. delimiting the fan-areas, where sediments may deposit;

3. imposing land-use limitations in endangered areas (future settlements);

4. imposing a risk assessment analysis on alluvial fans on a local scale to municipality authorities.

In 2001, the hazard assessment on the alluvial fans at a basin scale (about $25000 \mathrm{~km}^{2}$ ) has been made by following a geomorphological approach and by means of in-site evaluations or analysis of historical records. The hazard maps became a part of the PAI. The scale at which the assessments were made was necessarily adequate to the quality of available data, mainly that of maps at a scale 1:25000. According to norms of the hydrogeological arrangement plan, local municipalities are required to improve hazard mapping assessments, at a municipality scale (1:5000 or less), by more rigorous local studies. The ideal procedure to improve hazard mapping on the debris fans, that has been proposed since 2001 by the Autorità di Bacino del Fiume Po (Po River Watershed Authority - which is responsible for territorial planning, as far as hydrogeological disasters are concerned in the Po river basin) takes into account the role played by local authorities, the local awareness and responsiveness for natural disasters. Some guidelines have also been adopted at a regional scale, to propose updated methodologies for hazard mapping in mountainous areas.

As far as historical data are concerned, some documents show that during the 1977 flood event (Anselmo et al., 1978; Govi, 1978; Maraga and Mortara, 1977; Tropeano et al., 1999) another debris flow occurred in Villar Pellice, but with a much smaller magnitude than in 2008 (Lollino et al., 2008). The comparison of aerial photographs taken after the 1977 and the 2008 events, shows that the fan area affected by the 1997 debris flow was much smaller and the deposits were located mainly along the torrent. In 1977, the houses, shown in red in Fig. 6, did not suffer any damage. Moreover, during the 2000 flood event in the Pellice Valley, one of the most recent and destructive, no debris flows occurred in the Cassarot torrent. 


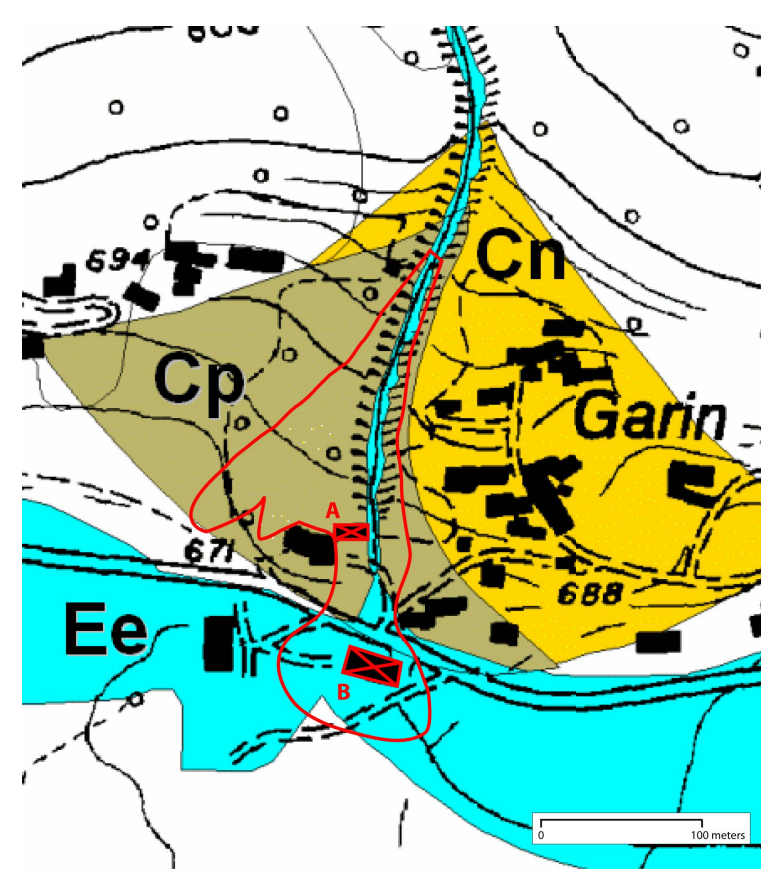

Fig. 5. Hazard mapping on the Villar Pellice fan. The area shown in the picture is taken by PAI (Autorità di Bacino del Fiume Po, 2001) and has the same extension of the box in Fig. 1. In this picture, the areas that are shown are classified by PAI as areas at risk: $\mathrm{CP}$ - area characterised by high debris flow hazard and partially protected; $\mathrm{Cn}$ - area characterised by medium debris flow hazard; Ee - area characterised by very high water flood hazard. The red line shows the limit of debris flow deposits; A and B are the two destroyed houses.

From the viewpoint of territorial planning, the available data and the field surveys carried out on the Cassarot torrent, allowed hazard mapping of the debris fan on a local scale, as indicated in Fig. 5. The mapped areas in Villar Pellice, that could be reached by a debris flow, were partially confirmed by the 2008 event. In particular, one of the destroyed houses (house A in Fig. 5) was in an area where the debris flow hazard was classified as "high" and "partially" protected (Cp areas, Fig. 5), while in the adjacent areas the hazard was classified as "medium" (Cn areas, Fig. 5). The other destroyed house (B, Fig. 5) was in an area where the flood hazard was classified as "very high" (Ee areas, Fig. 5).

In $\mathrm{Cp}$ areas, the regulations allow restructuring and enlargement for hygienic purposes and ordinary maintenance. In Ee areas, the regulations allow for demolition without reconstruction and ordinary maintenance. Countermeasures for hazard reduction can also be set up, but public administration is not obliged to build them and, thus, it acts according to the availability of funding. Territorial plans for hazard mapping (Autorità di Bacino del Fiume Po, 2001) do not impose civil protection countermeasures, that are mostly delegated to the municipal territorial plans.

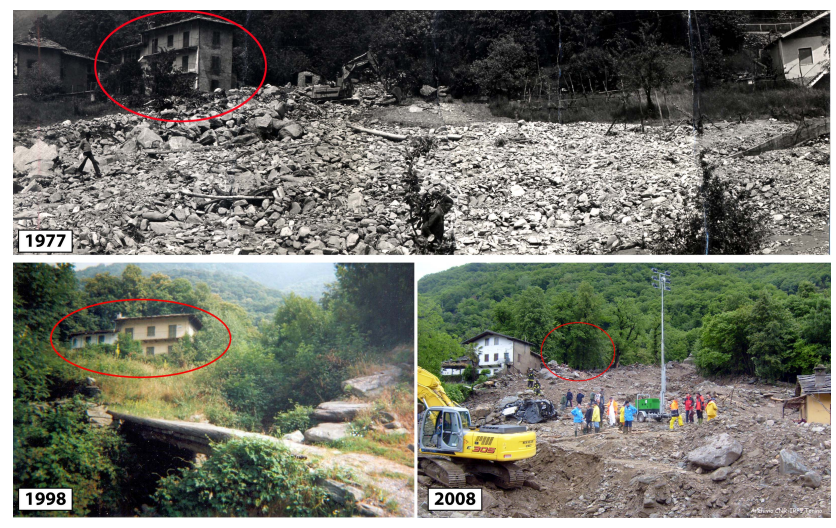

Fig. 6. Comparison of different images of the Garin alluvial fan: after the 1977 event - as the image shows, the debris flow affected a part of the fan without causing any damage to the house destroyed in 2008. In 1998 - the image shows the house destroyed in 2008 as it was until the day before the 2008 event; the image presents a very different situation compared to the following and it is particularly important because it allows us to evaluate which was the morphological context in which those who carried out an evaluation of the hazard of the area had to operate. The 2008 picture shows the post-event situation in all its drama.

If hazard mapping poses some questions of "rules and roles", real-time monitoring poses the question of "if" and "how" to intervene during potentially catastrophic events. According to the Italian regulations, the latter is mainly a civil protection task, that will be discussed in the following.

\section{Civil protection intervention strategy}

The civil protection system in the Piedmont Region has been greatly implemented after the severe geo-hydrological occurrance in 1994 (Susella et al., 1998; Luino, 1999) and 2000 (Tropeano et al., 2000). As a system, its main purpose, in addition to delivering immediate aid and rescuing people, is to provide prevision, prevention and education.

The system has its basis in the regional alert system for natural risk management, that issues a series of bulletins addressing two different aspects of risk management: the "criticality level" of the event and the "activities" to be performed by the authorities. This operative procedure is the consequence of the application of the so-called Augustus Method (Galanti, 1997), which has been recently implemented by the civil protection agency. This method was named after the emperor Augustus who was known to have said 2000 years ago that "the efficiency of planning is low when the complexity of the events is high". In this frame, the Augustus method is a very flexible and simple means which allows the splitting of the activities into their different components. 
According to ARPA, Piedmont has been divided into eleven alerting zones; for each of them a risk level is specified by the bulletin. By applying some meteorological models, on 28 May 2009 the ARPA established that in the Pellice Valley (and in all D zone) the risk level, for the next $36 \mathrm{~h}$, was rated "3" ("high criticality" level) on a scale that ranges from 1 to 3 . This level corresponds to the possible occurrence of "soil slips, debris flows and floodings". Since the bulletins were received, the Civil Protection Regional Department together with the regional and local authorities and the "centre for coordination of aid" (established in the Provinces hit by the atmospheric event) were forced to constantly keep in touch. The contacts took place through the operative centre of the Civil Protection Regional Department, located in Turin. The latter coordinates six different activities: (1) technical and scientific aid, (2) information to mass media, (3) volunteers (2113 men and 335 operational machines), (4) materials, (5) viability, and (6) logistics.

As far as the specific case of Garin is concerned, it must be noted that this site was taken into account by the civil protection system, but not with the use of instrumental control systems. The installation of warning systems (sirens or other monitoring and warning equipments) is sometimes adopted, but usually for cases that are characterised by a greater hazard level, which is often due to a higher frequency of occurrence.

In the specific case we are dealing with, the evaluation of the hazard was maybe underestimated (Fig. 6); the morphological evidences on the field and previous phenomena did not adumbrate such a high hazard level. These type of fans, thus, represent an open issue as far as the risk management is concerned, because their diffusion and their potential low activation level lead to the application of non-structural measures that require emergency management essentially based on the evacuation of the areas at risk. The application of such a strategy represents, however, a strong criticality, given the strict time intervals for the interventions and the difficulties in reaching the sites during the events. The idea of a preventive, generalized evacuation of all the sites at risk cannot be considered as an alternative solution because the areas that should be evacuated are very often too large, such as the area that the ARPA assigned the code 3 to for the May 2008 event: evacuating all the sites that had risk conditions similar to that of the Cassarot creek would have been impossible.

\section{Hazard management on alluvial fan: the limits of scientific knowledge and tools}

Due to the peculiar characteristics of debris flows, such as unpredictability and rapidity of occurrence, high propagation velocity, short duration and destructiveness, the task of dealing with real-time management is really difficult. This is particularly evident when a wide area such as the Pellice Valley $\left(293 \mathrm{~km}^{2}\right)$ which accounts for about 100 alluvial fans, is involved. In Piedmont only, however, the number of fans is 2400,800 of which are totally or partially urbanized. During the 19th and 20th centuries, 348 municipalities were hit by mud-debris flows. In the studied case, the ARPA bulletin (sent less than $24 \mathrm{~h}$ before the debris flow occurrence) could have given some hints of the possibility that debris flows could occur, even though in an area that is twice as large as the Pellice Valley. However, the bulletin was based on a rainfall forecasting at a regional scale and it could not give more precise indications on the exact location where the highest rainfall intensities might have occurred. In fact, the possibility of a warning system based on antecedent rainfall conditions and weather forecast (Wilson et al., 1993; Davies, 1997), is strongly limited by the extreme localization of certain meteorological events, such as the 29 May 2008 event. Uncertainty in rainfall forecasting could be reduced by shortening the forecast time (1-6h), but that would consequently reduce also the time available for civil protection interventions.

The variability of the rainfall triggering thresholds can also play an important role in explaining the difficulties in hazard management. This variability can be very high and its determination can also be complicated by other factors. For instance, in the studied case, it is highly unlikely that the rainfalls recorded in 1977 (when another debris flow occurred in the same creek) may allow a comparison with those recorded by the modern monitoring system. This is due to the different types of rain gauges employed and the different data acquisition time lag.

Moreover, the needs of civil protection countermeasures plays an important role in decision making. For example, automatic warning systems (generally based on a continuous measurement of rainfalls or on hydrographs) are probably more reliable for the protection of transportation routes than for the protection of buildings and villages, since it is simpler to impede in time the use of an infrastructure to a temporary user than to move in time an inhabitant from an endangered dwelling. As a matter of fact, leaving houses during a catastrophic event can show not to be the best solution, since it has already happened, as reported by Hungr et al. (1987), that people were swept away and killed while attempting to flee an endangered house while the house remained undamaged. In the examined case, however, it would not have been secure both leaving the house and staying in it, even though an automatic warning had been issued.

Therefore, the difficulty in using an event-triggered warning system is not a limit of the available technology. The latter, on the contrary, is continuously increasing and improving through research activities both in the field of monitoring (Arattano and Grattoni, 2000; Suwa et al., 2000; Genevois et al., 2000; Hanisch et al., 2003) and of development of warning systems (Chang, 2003; Liu and Chen, 2003).

As far as the territorial planning is concerned, the uncertainties in hazard mapping are also great. The estimation of the total potential magnitude of debris flows is a subject of 
wide debate (Rickenmann, 1999), as the simulation of the spreading of a debris flow on the fan. Regional regulations on this subject are quite complex and practitioners could suggest different hazard mappings of the areas on the same fan according to the different hazards that may be present. A hazard mapping based only on historical data could be deceptive, as it is shown by the comparison of the aerial photos of the 1977 debris-flow event and those of the 2008 event. On the other hand, the realization of structural countermeasures (deposition basins, check dams, channel linings) on all fans existing along the whole Pellice Valley would be either too expensive and also often impractical. Relocating houses and people to safer environments remains sometimes the most reasonable solution, but it is generally not well accepted by inhabitants. Therefore, territorial planning generally relies on a compromise among the needs of protection, of economics and of urban development.

All the uncertainties that affect assessments, forecasting and, indirectly, decision making, are due to a number of factors that range from the lack of data (hydrological data, DTMs, etc.), to the limitation of models (triggering models, rainfall thresholds) to a lack of a complete understanding of the processes (Ben Haim, 2001). Uncertainties increase dramatically when the time for decision making is reduced and is not assisted by a theory or some sort of criterion, but has to be done "with the rule of thumb".

Decision making that regards different aspects, such as the safeguard of human life and the protection of economy (goods, transportation routes, etc.), are generally in contrast to each other (Keeney and Raiffa, 1976) and often models that rely on a value hierarchy ("human life first") can reveal its incompleteness. Moreover, in spite of the enormous work that has been done on a scientific level, much more work still remains to be done to bridge the gap between science, research and reality (Ben Haim, 2001). A decision making theory to assist practitioners and officers is, therefore, needed, either in a real-time situation or in a planning regime. Research on this subject is ongoing.

Finally, the use of warning systems requires an accurate education of the interested population (Cheng et al., 1997). Clear signs exposing the risk conditions should be affixed on buildings and in the surroundings of endangered areas to warn inhabitants. Davies (1997) suggests that very good information is needed about the warning time reliably available and the time needed to reliably evacuate an area in order to make a decision as to whether event-triggered warning and evacuation is a suitable hazard mitigation strategy for a given site.

\section{Improvements of civil protection intervention strategy}

Given all the limitations and shortcomings of the present state of knowledge mentioned in the previous paragraph, the nowadays civil protection strategies in the Piedmont Region, nevertheless, need to be improved in order to manage events such as the May 2008 debris flow.

The steps should be the following:

1. Increase the risk perception of people living in the endangered areas. This should be pursued mainly by means of more education (periodical meetings, distribution of leaflets, realization of permanent documentation centres). People should be better informed about what to do during catastrophic events and made aware of the risk that can never be reduced to zero;

2. Local administrations should be organised and informed about what to do in potentially dangerous conditions, for different levels of risk, as indicated by ARPA bulletins; this would imply the creation of protocols, that would reduce false or subjective perceptions of risks;

3. Mayors of small municipalities should be helped to take decisions in real time by experts, chosen for each municipality or at the watershed basin scale; these could play an important role during the time lag between the issue of the ARPA bulletin and the occurrence of potentially dangerous conditions;

4. Improvement of reactivity. The Civil Protection Regional System has already greatly improved between the 1994 and 2000 severe geo-hydrological events. It has recently launched, according to the 2004 national directive on hydrogeological risk, a flood management project. This consists of watching, during a crisis, several critical points that in the last decades have required civil protection interventions. The Piedmont Region detected 115 hydrogeological critical points, so far, that will be watched for forecasting severe meteorological events. The project has already been administratively approved and is going to be put in practice during 2010. The project provides for the direct watch of these critical points performed during ordinary and emergency times. In this way, it could be possible to activate the civil protection reaction during natural events or immediately before them. So it will be feasible to intervene rapidly, reducing as much as possible the detrimental effects of hydrogeological phenomena. 


\section{Conclusions}

The debris flow that occurred in Piedmont in May 2008 shows that the present system for territorial hazard mapping and civil protection interventions needs to be improved. Actually, even if some of the effects of the 29 May 2008 catastrophic event that caused four casualties were correctly estimated (such as the probability of occurrence of debris flows, soil slips and also which were the potentially affected areas), the studied case shows the need for an improvement in spatial and temporal forecasting, action protocols, dissemination of hazard alerts and timely decision making.

Uncertainty related to debris-flow occurrence, magnitude and management, together with the meagerness of time available to make decisions in real time, are the most evident difficulties to overcome.

However, improvements are possible to help mayors of small municipalities make decisions, by means of experts that can help them on the basis of protocols, volunteers and civil protection plans. These experts could carry on or supervise the observation of the most critical points of an area and so be ready for direct intervention. This improvement might significantly increase the performance of the existing intervention strategies and protocols. Similar experts are already present in the so called Avalanches commissions, that assist the mountain communities in the mitigation of the avalanche risk. Peoples' perception of risks should also be increased, on the basis of appropriate education and direct involvement.

Acknowledgements. The authors thank their colleagues G. Lollino and G. Mortara for their support during the first phase of the event analysis; the authors thank also A. Glauco for providing the 1998 picture present in Fig. 6.

Edited by: P. Allasia

Reviewed by: M. Parise and J. Coe

\section{References}

Anselmo, V.: L'evento alluvionale del 19 maggio 1977 nei bacini del Pellice e del Germanasca, XVI Hydraulics engineering Italian conference, 1-12, 1978 (in Italian).

Arattano, M. and Grattoni, P.: Using a fixed video camera to measure debris-flow surface velocity, in: Proceedings of the Second International Conference on Debris-flow Hazards Mitigation: Mechanics, Prediction, and Assessment, Taipei, 16-18 August 2000, edited by: Wieczorek, G. and Naeser, N., A.A. Balkema, Rotterdam, 273-281, 2000.

ARPA Piemonte: Rapporto preliminare sull'evento alluvionale del 28-30 maggio 2008 - Parte prima, analisi meteo-idrologica, 2008, available at: http://www.arpa.piemonte.it/modules.php? op=modload $\backslash \&$ name=Downloads $\backslash \&$ file=index $\backslash \&$ req=getit $\backslash$ \&lid=2561, last access: 10 December 2009 (in Italian).

Autorità di Bacino del fiume Po: Piano stralcio per l'Assetto Idrogeologico (hydrogeological arrangement plan - PAI), 2001 (in Italian).
Barredo, J. I.: Major flood disasters in Europe: 1950-2005, Nat Hazards, 42, 125-148, 2007.

Ben Haim, Y.: Information-Gap Theory: Decisions Under Severe Uncertainty, Academic Press, London, 384 pp., 2001.

Chang, S. Y.: Evaluation of a system for detecting debris flows and warning road traffic at bridges susceptible to debris flow hazard, in: Proceedings of the Third International Conference on Debris-flow Hazards Mitigation: Mechanics, Prediction, and Assessment, edited by: Rickenmann, D. and Chen, C. L., Millpress, Rotterdam, 731-742, 2003.

Cheng, J. D., Wu, H. L., and Chen, L. J.: A comprehensive debris flow hazard mitigation program in Taiwan, in: Debris-flow Hazard Mitigation: Mechanics, Prediction, and Assessment, edited by: Chen, C.-L., Proc. - First International Conference, ASCE, San Francisco, California, 93-102, 7-9 August 1997.

Collins, T. K.: Debris flows caused by failure of fill slopes: early detection, warning, and loss prevention, Landslides, 5, 107-120, 2008.

Davies, T. R.: Using hydroscience and hydrotechnical engineering to reduce debris flow hazards, in: Debris-flow hazard mitigation: mechanics, prediction and assessment, edited by: Chen, C. L., ASCE, New York, 787-810, 1997.

Franzi, L. and Bianco, G.: Esame quantitativo di un intenso evento meteorico con conseguente colata di detrito e suo inquadramento nella pluviometria locale precedente, XXVIII Hydraulics engineering Italian conference, 469-476, 2002 (in Italian).

Galanti, E.: Il metodo Augustus, DPC informa, 2(4), 1-35, 1997 (in Italian).

Genevois, R., Tecca, P. R., Berti, M., and Simoni, A.: Debris-flow in the Dolomites: Experimental data from a monitoring system, in: Proceedings of the Second International Conference on Debrisflow Hazards Mitigation: Mechanics, Prediction, and Assessment, edited by: Wieczorek, G. and Naeser, N., A.A. Balkema, Rotterdam, 283-291, 2000.

Govi, M.: Gli eventi alluvionali del 1977 in Piemonte: problemi di protezione idrogeologica, in: Proc. Conf. "Pianificazione territoriale e geologia", Regione Piemonte - Dip. Organizzazione e gestione territorio e Assessorato Pianificazione Territorio, 37 45, 1978 (in Italian).

Guzzetti, F., Peruccacci, S., Rossi, M., and Stark, C. P.: The rainfall intensity-duration control of shallow landslides and debris flows: an update, Landslides, 5(1), 3-17, 2008.

Hanisch, J., Ergenzinger, P., and Bonte, M.: Dumpling-an "intelligent" boulder for studying internal processes of debris flows, in: Proceedings of the Third International Conference on Debrisflow Hazard Mitigation: Mechanics, Prediction, and Assessment,edited by: Rickenmann, D. and Chen, C. L., Millpress, Rotterdam, 843-849, 2003.

Hungr, O., Evans, S. G., Bovis, M., and Hutchinson, J. N.: Review of the classification of landslides of the flow type, Environ. Eng. Geosci., 7(3), 1-18, 2001.

Hungr, O., Morgan, G. C., VanDine, D. F., and Lister, D. R.: Debris flow defenses in British Columbia, Geol. S. Am. - Rev. Eng. Geol., 7, 201-222, 1987.

Keeney, R. and Raiffa, H.: Decisions with Multiple Objectives: Preferences and Value Tradeoffs, Willey, New York, 516 pp. 1976.

Liu, K. F. and Chen, S. C.: Integrated debris flow monitoring system and virtual center, in: Proceedings of the Third International 
Conference on Debris-flow Hazard Mitigation: Mechanics, Prediction, and Assessment, edited by: Rickenmann, D. and Chen, C. L., Millpress, Rotterdam, 767-774, 2003.

Lollino, G., Mortara, G., Luino, F., and Giordan, D.: Colata detritica torrentizia in località Garin (Comune di Villar Pellice - TO) Repot of event, 15 pp., available at: http://www.irpi.to.cnr.it/documenti/CNR-RPI_Rapporto\% 20Garin_9\%20giugno\%202008.pdf (last access: 10 December 2009), 2008 (in Italian).

Luino, F.: The flood and landslide event of November 4-6, 1994 in Piedmont Region (North-West Italy): causes and related effects in Tanaro Valley, in: XXII General Assembly European Geophysical Society, Vienna (Austria), 21-25 April 1997, Elsevier Science Ltd, 24(2), 123-129, 1999.

Luino, F.: Sequence of instability processes triggered by heavy rainfall in northwestern Italy, Geomorphology, 66, 13-39, 2005.

Maraga, F. and Mortara, G.: Modificazioni dell'alveo, e trasporto solido al fondo nel T. Pellice in riferimento alla piena del 1920 maggio 1977, in: Proc. conf. "Misure del trasporto solido al fondo dei corsi d'acqua: problemi per una modellistica matematica", 1-16, 1977.

Moscariello, A., Marchi, L., Maraga, F., and Mortara, G .: Alluvial fans in the Alps: sedimentary facies and processes, IAS Special Publication, 32, 141-66, 2002.

Rickenmann, D.: Empirical Relationships for Debris Flows, Nat. Hazards, 19(1), 47-77, 1999.

Susella, G., Bellardone, G., Brovero, M., Colombo, I., Magosso, P., Negro, N., Piccioni, C., Troisi, C., Turroni, E., and Ziliani, A.: Eventi alluvionali in Piemonte, Artistica Savigliano, Torino, 1998
Suwa, H., Yamakoshi, T., and Sato, K.: Relationship between debris-flow discharge and ground vibration, in: Proceedings of the Second International Conference on Debris-flow Hazards Mitigation: Mechanics, Prediction, and Assessment, edited by: Wieczorek, G. and Naeser, N., A.A. Balkema, Rotterdam, 311318, 2000.

Tiranti, D., Bonetto, S., and Mandrone, G.: Quantitative basin characterisation to refine debris-flow triggering criteria and processes: an example from the Italian Western Alps, Landslides, 5(1), 45-57, 2008.

Tropeano, D., Govi, M., Mortara, G., Turitto, O., Sorzana, P. F., Negrini, G., and Arattano, M.: Eventi alluvionali e frane nell'Italia Settentrionale. Periodo 1975-1981, CNR-IRPI e CNR-GNDCI, Pubblicazione n. 1927, 279 pp., 1999 (in Italian).

Tropeano, D., Luino, F., and Turconi, L.: Evento alluvionale del 14-15 ottobre nell'Italia Nord-Occidentale, Fenomeni ed effetti, GEAM, XXXVII, n. 4, 203-216, 2000 (in Italian).

Wilson, R. C., Mark, R. K., and Barbato, G.: Operation of a Realtime warning system for debris flows in the S. Francisco Bay Area, California, in: ASCE 1993 National Conference on Hydraulic Engineering and International Symposium on Engineering Hydrology. San Francisco, California, 25-30 Luglio 1993, edited by: Shen, H. W., Su, S. T., and Wen, F., American Society of Civil Engineers (ASCE), New York, Hyd. Eng., 2, 1592-1597, 1993. 